\title{
Analytical Solution of Arbitrary Loaded Spatial Pile Group
}

\author{
Petar Santrac ${ }^{*}$, Zeljko Bajic ${ }^{2}$ \\ 1 Department of Geotechnics, Faculty of Civil Engineering, University of Novi Sad, Kozaracka 2A, 24000 Subotica, Serbia \\ 2 GeoEXPERT d.o.o., Brace Jugovic 9/1, 24000 Subotica, Serbia \\ *Corresponding author, e-mail: santrac@geoexpert.rs
}

Received: 26 August 2019, Accepted: 31 January 2019, Published online: 20 February 2020

\begin{abstract}
This paper presents an analytical method for the calculation of the arbitrary loaded spatial pile group fixed or/and hinge jointed into a rigid cap. The method uses the vector and matrix procedures to derive spatial equations of equilibrium, in which unknown componential displacements appear. The stiffness coefficients in the equations can be determined analytically, numerically or by pile load test. The pile group effect are estimated approximately, reducing the piles stiffness coefficients which depend on pile position and its mutual distances.
\end{abstract}

\section{Keywords}

pile group, piles interaction, axially loaded pile, laterally loaded pile

\section{Introduction}

The calculation of the displacement and bearing capacity of the pile group under arbitrary load, due to the act of a large number of different factors is probably one of the most complex geotechnical problem. Today, a very sophisticated numerical models are available in this area, which include soil non-homogeneity and non-linearity, nonlinear pile-soil interface, the influence of the pile installation in the ground, the piles spatial arrangement and dimensions, the character of the load (static, cyclic, dynamic), the loading condition (drained, undrained or transient) and others.

At first glance, this software achievements, especially in the absence of good theoretical background and practical experience, provides to the users of the software an illusion of limitless analytical power. To avoid this trap, it should be borne in mind, that however sophisticated the software is, it cannot replace the intuition, experience, critical engineering approach, well-designed solution and ability to identify the factors that significantly affect the results. After all, the history witnesses impressive steady buildings, built with modest knowledge in the field of mechanics and material resistance, mainly based on experience and intuition. It is unnecessary to prove or it is well known, that engineering calculation is always approximative, so the well-designed, logical and simply dimensioned constructions are always better than a poorly conceived one that is dimensioned by using a very sophisticated software.
Furthermore, to obtain qualitative and acceptable results by using sophisticated or simple numerical models it is very important to have a qualitative material data, primarily for soil. The procedure to obtain qualitative soil parameters are a process, that begins with a well-designed scope and type of site investigation, well-executed site and laboratory tests and finally with expert elaboration and interpretation of the obtained test results. No badly done or missing step in this process can be subsequently fixed, not even by applying the most sophisticated software. In other words, qualitative material parameters are always necessary, booth in the case of simple or sophisticated numerical models (software). However, if the calculations are more complex, it is logical to expect better results, with greater numbers of material parameters and more complex process of determining them, and vice versa. With all this in mind, in parallel with the development of complex numerical models, there is always present an effort to constantly review and improve the already existing simple models. The reason for this lies in their simple application and accumulated experience gained by measurements, comparisons and back analyses.

When it comes to geotechnics, the basis of simple soil models is the Winkler model, the elastic continuum model, their mutual combinations and a combination with the limit state model. Today, there are a lot of published works in this area, and the authors of this paper tried to make 
contribution in this field. It is well known that Winkler model replaces the soil around the pile with a series of linearly or non-linearly deformable unbounded springs. This kind of soil model has a very wide application in geotechnical calculations, such as beams, mats and slabs on deformable foundation, flexible retaining walls, piles and pile group.

The basic drawback of the model is that the deformation of a single spring has none effects on the other surrounding springs, and that the spring deformation characteristics expressed by the so-called modulus of soil reaction, is not a fundamental soil parameter. Based on very extensive study, Terzaghi [1] gave first recommendations for determination of the modulus of reaction. For piles in clay, he correlated the modulus of reaction with the one-axial soil strength, and for the piles in sand, with the relative density and moisture. The indicated values of the modulus of reaction are valid for the load level up to about $1 / 2$ of the failure force, taking into account the long-term displacement due to creep. On the basis of full scale and model tests, it is determined that the back-calculated modulus of reaction can be up to 5 times larger than those of Terzaghi, so in practice, at least doubled values are recommended (Reese et al. [2], Robinson [3], Scott [4]).

One of the first systematic solutions to the problem of a beam on Winkler's foundation, which is convenient for practical application, was given by Hetényi [5]). In order to obtain a solution for the pile, it is sufficient that the horizontal beam, that is end-loaded by force and moment, is rotated by $90^{\circ}$. In the simplest case, the modulus of reaction is constant, and as such it is good approximation for the pile in the layer of over-consolidated clay. However, for the pile in the layer of sand or normally consolidated clay, the more complex model is introduced in which the modulus grows linearly in depth. An approximate analytical solution for a rigid and flexible pile in a layer whose modulus grows linearly was performed by Barber [6] while Broms [7] gave a diagrams for calculating the bearing capacity and displacements of a horizontally loaded pile in sands, normally or over consolidated clays.

Matlock [8], Reese et al. [9], Bransby [10], Ashour and Ardalan [11] improved the Winkler model by introducing a nonlinear contact, taking into account the deformability and ultimate strength of the soil (sand or clay) along the pile shaft. This concept is known as the "p-y method of lateral load transfer", and is now embedded in a large number of commercial software. A similar method, using the degradation of soil modulus with the growth of deformation, was given by Prakash and Kumar [12], Bowles [13], Hsiung [14], Amar et al. [15], Guo [16], modelling the soil at shaft with ideally elastoplastic springs.

A completely different approach, based on soil modelling as a linear elastic continuum, was given by Butterfield and Banerjee [17], Poulos and Randolph [18], Randolph [19], Zhang et al. [20], Higgins et al. [21] and others. Unlike Winkler's model, the model of the elastic continuum is defined by two fundamental physical characteristics of the soil, that is, the modulus of elasticity and the Poisson coefficient, which can be determined by test. Since the continuum model is much more complicated for computation than Winkler's, there are only approximate numerical solutions, which are based on finite difference or finite elements method. The model of the elastic continuum describes the behaviour of the soil much better, because it implicitly implies that the effect at one point of the continuum extends to all the surrounding points inversely proportional to distance. However, what enables a better description of soil behaviour, requires a more complicated mathematical methods for computation.

Most of the incipient papers were limited to the calculation and description of the behaviour of an individual pile due to vertical or horizontal load and bending moment. However, the load from the object is almost as a rule transmitted to a group rather than a single pile, and the behaviour of the pile group is different than the behaviour of a single one. The computation of the displacement of the pile group is a more complicated task, so the results of the calculations and measurements show significantly higher deviations than in the case of a single pile. A large number of researchers tried to solve the problem of pile group, on the bases of the Winkler method, which already had popularity and wide application for a single pile. In order to solve the basic drawback of the Winkler model when it comes to the pile group, the solution was sought in selective reduction of soil reaction modulus around the pile in dependence of their position in the group. For a vertically loaded pile group, selective reductions are carried out through factors of interaction, which can be approximated by analytical Randolph and Wroth [22], Mandolini and Viggiani [23] or numerical methods, or on the basis of pile load test. In a horizontally loaded group, a selective reduction concept is also widely used, known as the "method of p-multiplier". There are number of papers in that area, which were published by Mokwa [24], Ilyas et al. [25], Ashour and Norris [26] and others. 
In the case of the pile group in elastic continuum, the best known solutions are those proposed by Buterfild and Banerjee [17], Banerjee [27], Poulos [18, 28], Mandolini [23, 29], McCabe and Sheil [30] and others. Unlike the Winkler method, the calculation of the interaction between the piles in elastic continuum does not require additional work or modifications, since the continuum implicitly assumes the spread of the impact from one pile to all adjacent piles in the group.

In this paper, an attempt was made to provide a certain contribution to the application of the simple Winkler model. The advantage over the sophisticated software is simplicity, price and low number of soil parameters. This was done by formulating of a simple mathematical framework for force and displacement computation for the arbitrary spaced and loaded pile group, connected by an ideally rigid cap. For a small pile group (e.g. under the column) the assumption of an ideally rigid cap is almost always justified.

The method is very simple and can be used with basic programming knowledge in Excel, which is available in the standard Microsoft Office.

Programming can be done explicitly in the worksheet itself or for advance users in the visual-basic background code. The entire algorithm of the calculation can be done using matrix and vector methods.

The paper presents in detail the derivation of matrix equations, which analytically link the load, displacement and rotation of the pile head with loads and moments acting on the cap. Piles can have an arbitrary arrangement, dimensions and inclinations in the ground, and the cap can be arbitrarily loaded with forces and moments in the direction of all three coordinate axes. The elements of the matrix of stiffness in the piles local coordinate system can be assigned directly, determined analytically, numerically, or on the basis of pile load test. If the soil is homogeneous in depth, analytical solutions for a constant and linearly variable modulus of reaction, or approximate solutions for a constant and linearly varying modulus of elasticity, can be applied. In layered and non-linearly deformable soil the elements of the pile stiffness matrix can be determined approximately up to the workload level and then inserted directly into the pile stiffness matrix. The same applies to the elements of the stiffness matrix that are determined from the load-displacement curve obtained by pile load test. The interaction between piles is put into the computation indirectly, through selective reduction of the soil modulus.
The main drawback of the presented mathematical model in relation to the more complex one is the inability to accurately include the pile interactions. As usually, it was introduced in approximate manner, reducing the soil shear and lateral modulus of reaction around each pile in group.

\section{Forces in piles in function of the cap displacement}

\subsection{Pile-cap kinematic and compatibility equations}

Displacements of the ideally rigid cap is completely determined in the spatial coordinate system by two vectors, i.e. translation $\{\rho\}$ and rotation $\{\theta\}$. The global coordinate system is usually tied to the center of gravity of the pile's cap. In the developed form, the shift of the cap is determined by the 3 displacement components in the directions of the coordinate axes and the 3 components of the rotation around the axis of the global coordinate system.

In Fig. 1 the translation and the rotation of the cap around the point $\mathrm{O}$ are denoted by vectors $\{\rho\}$ and $\{\theta\}$. The position of an arbitrary pile ( $i$ ) fixed into ideally rigid cap is marked by radius vector $\{r\}$, and the pile axis by unit vector $\{l\}$.

Since the pile is at a distance $\{r\}$ from the rotation center $(\mathrm{O})$, in addition to translation and rotation obtained directly from the cap, the pile head also has additional movement whose direction and intensity is determined by the vector product $\{\theta\} \times\{r\}$.

Apart from the global coordinate system the local system which is related to the piles are also used. The local coordinate axes coincide with the pile axis and the normal on pile axis. The pile axis and the normal on the pile axis lies in the plane of pile head displacement and bending.

Fig. 2 shows the components of pile head displacement and rotation in the local coordinate system. The components of displacement and rotation of an ideally rigid pile

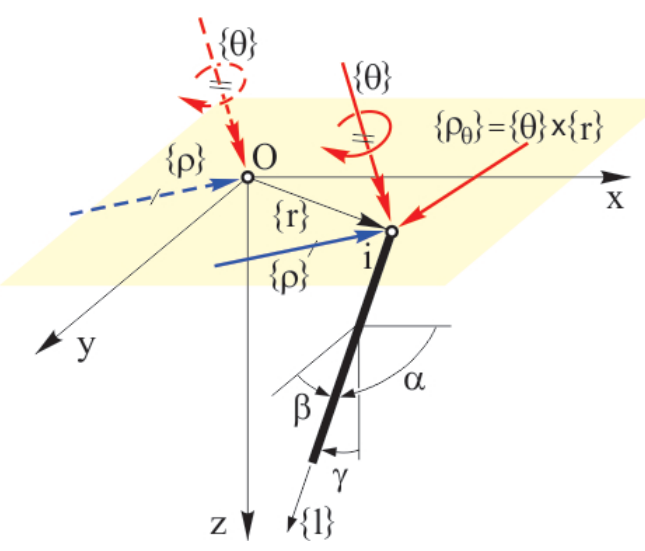

Fig. 1 Vectors of pile cap and pile movement and rotation 


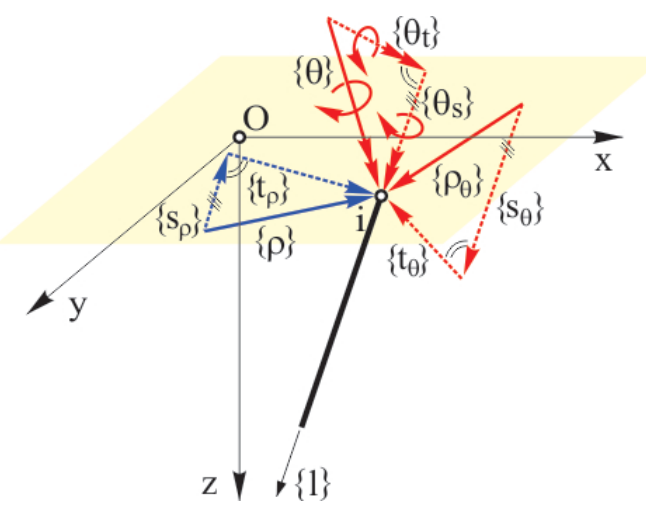

Fig. 2 Vector components of pile movement and rotation

cap, $\{\rho\}$ and $\{\theta\}$, radius vector $\{r\}$ and unit vector $\{l\}$ are shown in the global coordinate system by the following Eq. (1):

$\{\rho\}=\left\{\begin{array}{l}u \\ v \\ w\end{array}\right\},\{\theta\}=\left\{\begin{array}{l}\theta_{x} \\ \theta_{y} \\ \theta_{z}\end{array}\right\},\{r\}=\left\{\begin{array}{l}x \\ y \\ z\end{array}\right\},\{l\}=\left\{\begin{array}{l}\cos \alpha \\ \cos \beta \\ \cos \gamma\end{array}\right\}$.

In order to determine the forces and moments on the pile head, in a linearly or non-linearly deformable medium with known stiffness parameters, due to piles cap displacement and rotation, it is necessary to establish a relation between pile head displacement and rotation in the local coordinate system and piles cap displacement and rotation in the global coordinate system. The number of local coordinate systems is equal to the number of piles, and the transformation from the local to the global coordinate system is determined by the global coordinates of the pile head $\{r\}$ and the angles $\{l\}$ between the pile axis and global coordinate axes. The components of the translational of the pile head in the direction of the pile axis $\left\{s_{\rho}\right\}$ and in the direction of the normal on the pile axis $\left\{t_{\rho}\right\}$, in the local coordinate system and the piles cap can be displayed in a vector or matrix form by Eq. (2). The terms $s_{r}$ and $t_{r}$ in the equation are the projections of the pile head displacement vector in the direction of the local coordinate axes.

$$
\begin{aligned}
& \left\{s_{\rho}\right\}=\{l\}\{l\}^{T}\{\rho\}=\left[l^{2}\right]\{\rho\} \\
& \left\{t_{\rho}\right\}=\{\rho\}-\left\{s_{\rho}\right\}=\left([I]-\left[l^{2}\right]\right)\{\rho\}=\left[I^{*}\right]\{\rho\} \\
& {\left[I^{*}\right]=[I]-\left[l^{2}\right]}
\end{aligned}
$$

In the above equations, $[I]$ is the unit matrix and $\left[l^{2}\right]$ is:

$$
\left[l^{2}\right]=\left[\begin{array}{ccc}
\cos ^{2} \alpha & \cos \alpha \cdot \cos \beta & \cos \alpha \cdot \cos \beta \\
\cos \beta \cdot \cos \alpha & \cos ^{2} \beta & \cos \beta \cdot \cos \alpha \\
\cos \gamma \cdot \cos \alpha & \cos \gamma \cdot \cos \beta & \cos ^{2} \gamma
\end{array}\right] .
$$

The pile cap rotation $\{\theta\}$, cause pile head rotation $\{\theta\}$ and shift $\left\{\rho_{\theta}\right\}$, in proportion to the product $\{\theta\} \times\{\mathrm{r}\}$.

$$
\left\{\rho_{\theta}\right\}=\{\theta\} \times\{r\}=\left[\otimes_{r}\right]\{\theta\}, \quad\left[\otimes_{r}\right]=\left[\begin{array}{ccc}
0 & z & -y \\
-z & 0 & x \\
y & -x & 0
\end{array}\right]
$$

The components of the pile head translational vector $\left\{\rho_{\theta}\right\}$ due to cap rotation, in the direction of the pile axis $\left\{s_{\theta}\right\}$ and in the direction normal to the pile axis $\left\{t_{\theta}\right\}$, can be expressed by Eq. (4).

$$
\begin{aligned}
& \left\{s_{\theta}\right\}=\left[l^{2}\right]\left\{\rho_{\theta}\right\}=\left[l^{2}\right]\left[\otimes_{r}\right]\{\theta\} \\
& \left\{t_{\theta}\right\}=\left\{\rho_{\theta}\right\}-\left\{s_{\theta}\right\}=\left[I^{*}\right]\left[\otimes_{r}\right]\{\theta\}
\end{aligned}
$$

The components of the pile head displacement vector due to translation and rotation of the piles cap is:

$$
\begin{aligned}
& \{s\}=\left\{s_{\rho}\right\}+\left\{s_{\theta}\right\}=\left[l^{2}\right]\{\rho\}+\left[l^{2}\right]\left[\otimes_{r}\right]\{\theta\} \\
& \{t\}=\left\{t_{\rho}\right\}+\left\{t_{\theta}\right\}=\left[I^{*}\right]\{\rho\}+\left[I^{*}\right]\left[\otimes_{r}\right]\{\theta\} .
\end{aligned}
$$

The pile head total displacement includes the translation according to Eq. (5) and the rotation due to cap rotation. The vector of the pile head rotation should be separated into two components: the rotation in the direction $\left\{\theta_{s}\right\}$ which causes torsion and in the direction normal to the axis $\left\{\theta_{t}\right\}$ that causes bending. The expression for the components of the pile head rotation is given by Eq. (6).

$$
\begin{aligned}
& \left\{\theta_{\mathrm{s}}\right\}=\{\mathrm{I}\}\{\mathrm{I}\}^{\mathrm{T}}\{\theta\}=\left[\mathrm{I}^{2}\right]\{\theta\} \\
& \left\{\theta_{\mathrm{t}}\right\}=\{\theta\}-\left\{\theta_{\mathrm{s}}\right\}=\left([\mathrm{I}]-\left[\mathrm{I}^{2}\right]\right)\{\theta\}=\left[\mathrm{I}^{*}\right]\{\theta\}
\end{aligned}
$$

\subsection{The link between cap displacement and pile head forces in local coordinate system}

Based on the pile head displacement vector $\{s\}$ and $\{t\}$ and pile head rotation $\left\{\theta_{s}\right\}$ and $\left\{\theta_{t}\right\}$, the intensity of the normal $\{N\}$ and the transversal force $\{T\}$, the bending $\{M\}$ and the torsional moment $\{M\}$ on the pile head, in the local coordinate system can be determined by Eq. (7).

$\left\{\begin{array}{c}N \\ T \\ M \\ \mathfrak{M}\end{array}\right\}=\left[\begin{array}{cccc}K_{N s} & 0 & 0 & 0 \\ 0 & K_{T t} & K_{T \theta} & 0 \\ 0 & K_{M t} & K_{M \theta} & 0 \\ 0 & 0 & 0 & K_{\mathfrak{M} \theta}\end{array}\right]\left\{\begin{array}{c}s \\ t \\ \theta_{t} \\ \theta_{s}\end{array}\right\}, \begin{aligned} & \left\{P_{p}\right\}=\left[K_{p}\right]\left\{U_{p}\right\} \\ & \left\{U_{p}\right\}=\left[F_{p}\right]\left\{P_{p}\right\}\end{aligned}$

$N, T, M$ and $M$ are the components of the pile head force $\left\{P_{p}\right\}$, and $s, t, \theta_{t}$ and $\theta_{s}$ are the components of the pile head displacement vector in the local coordinate system. $\left[K_{p}\right]$ and $\left[F_{p}\right]$ are the matrix of stiffness and flexibility of the 


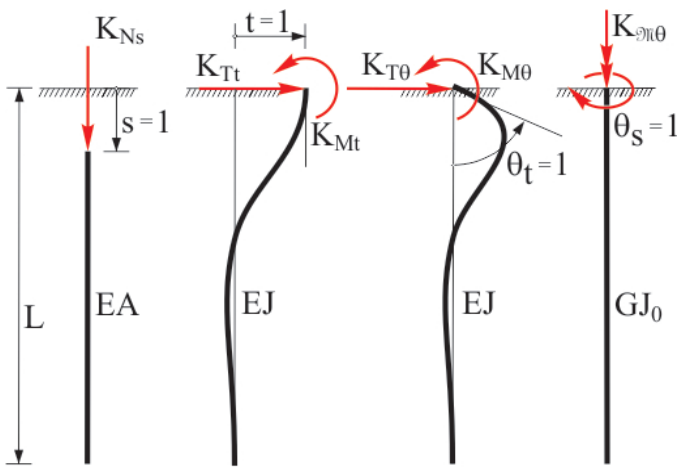

Fig. 3 The physical meaning of the elements of the stiffness matrix $\left[K_{p}\right]$

pile-soil. The torsional stiffness $K_{M \theta}$ is often small related to the rigidity of the resistance to lateral movement of the piles away from the axis of rotation, and can be ignored. The physical meaning of the stiffness is shown in Fig. 3.

The stiffness coefficients $K_{N s}, K_{T t}, K_{T \theta}, K_{M t}, K_{M \theta}$ and $K_{M \theta}$ can be described by the following way:

$K_{N s}=$ The normal force at the pile head, caused by unit axial displacement $s=1$, without lateral displacement $(t=0)$, bending or torsion $\left(\theta_{s}=0, \theta_{t}=0\right)$.

$K_{T t}=$ The transversal force at the pile head, caused by unit lateral displacement $t=1$, without axial displacement $(s=0)$, bending or torsion $\left(\theta_{s}=0, \theta_{t}=0\right)$.

$K_{T \theta}=$ The transversal force at the pile head, caused by unit bending $\theta_{t}=1$, without axial or lateral displacement $(s=0, t=0)$, or torsion $\left(\theta_{s}=0\right)$.

$K_{M t}=$ The bending moment at the pile head, caused by unit lateral displacement $t=1$, without axial displacement $(s=0)$, bending or torsion $\left(\theta_{s}=0, \theta_{t}=0\right)$.

$K_{M \theta}=$ The bending moment at the pile head, caused by unit bending $\theta_{t}=1$, without axial or lateral displacement $(s=0, t=0)$, or torsion $\left(\theta_{s}=0\right)$.

$K_{M \theta}=$ The torsional moment at the pile head, caused by unit torsion $\theta_{s}=1$, without axial/lateral displacement $(s=0, t=0)$, or bending $\left(\theta_{t}=0\right)$.

Stiffness coefficients for a single pile, in general, depend on the load level, soil deformability, pile-cap connection (fixed or hinged), elasticity modulus, dimensions and pile cross-section and shape.

\subsection{The link between cap displacement and pile head forces in global coordinate system}

The Eq. (7) is applicable for forces and displacements acting at the same plane. The general form of the Eq. (7), which links the forces and moments at pile head with the displacements and rotations of the piles cap in a global coordinate system is represented by Eqs. (8) and (9).

$$
\begin{aligned}
\{N\} & =K_{N s}\{s\}=K_{N s}\left[l^{2}\right]\{\rho\}+K_{N s}\left[l^{2}\right]\left[\otimes_{r}\right]\{\theta\} \\
\{T\} & =K_{T t}\{t\}+K_{T \theta}\{\theta\} \times\{l\}= \\
& =K_{T t}\left[I^{*}\right]\{\rho\}+\left(K_{T t}\left[I^{*}\right]\left[\otimes_{r}\right]+K_{T \theta}\left[\otimes_{l}\right]\right)\{\theta\} \\
\{M\} & =K_{M t}\{l\} \times\{t\}+K_{M \theta}\left\{\theta_{t}\right\}= \\
& =-K_{M t}\left[\otimes_{l}\right]\{t\}+K_{M \theta}\left\{\theta_{t}\right\}= \\
& =-K_{M t}\left[\otimes_{l}\right]\{\rho\}-\left(K_{M t}\left[\otimes_{l}\right]\left[\otimes_{r}\right]-K_{M \theta}\left[I^{*}\right]\right)\{\theta\} \\
\{\mathfrak{M}\} & =K_{\mathfrak{M} \theta}\left\{\theta_{s}\right\}=K_{\mathfrak{M} \theta}\left[l^{2}\right]\{\theta\}
\end{aligned}
$$

For the hinged pile-cap connections, the coefficients of stiffness $K_{T \theta}, K_{M t}, K_{M \theta}$ and $K_{M \theta}$ for those connections are zero. If all the connections between the piles and the cap are hinged, Eq. (8) is reduced to much simpler form:

$$
\begin{aligned}
& \{N\}=K_{N s}\{s\}=K_{N s}\left[l^{2}\right]\{\rho\}+K_{N s}\left[l^{2}\right]\left[\otimes_{r}\right]\{\theta\} \\
& \{T\}=K_{T t}\{t\}=K_{T t}\left[I^{*}\right]\{\rho\}+K_{T t}\left[I^{*}\right]\left[\otimes_{r}\right]\{\theta\} \\
& \{M\}=\{0\} \\
& \{\mathfrak{M}\}=\{0\} .
\end{aligned}
$$

Vector products in the Eq. (8) can be represented in the following matrix form:

$$
\begin{aligned}
& \{\theta\} \times\{l\}=\left[\otimes_{l}\right]\{\theta\} \\
& \{l\} \times\{t\}=-\left[\otimes_{l}\right]\{t\}
\end{aligned},\left[\otimes_{l}\right]=\left[\begin{array}{ccc}
0 & \cos \gamma & -\cos \beta \\
-\cos \gamma & 0 & \cos \alpha \\
\cos \beta & -\cos \alpha & 0
\end{array}\right] .
$$

Equation (8) links the normal $\{N\}$ and transversal force $\{T\}$, the bending $\{M\}$ and torsional moment $\{M\}$ with the vectors of displacement $\{\rho\}$ and rotation $\{\theta\}$ of the pile cap. All terms are expressed in a global coordinate system. The Eq. (8) can be shown by the matrix of sub-matrix:

$$
\left\{\begin{array}{l}
\{N\} \\
\{T\} \\
\{T\} \\
\{\mathfrak{M}\}
\end{array}\right\}=\left[\begin{array}{ll}
K_{N s}\left[l^{2}\right] & K_{N s}\left[l^{2}\right]\left[\otimes_{r}\right] \\
K_{N s}\left[l^{2}\right]\left[\otimes_{r}\right] & K_{T t}\left[I^{*}\right]\left[\otimes_{r}\right]+K_{T \theta}\left[I^{*}\right] \\
-K_{M t}\left[\otimes_{l}\right] & -K_{M t}\left[\otimes_{l}\right]\left[\otimes_{r}\right]-K_{M \theta}\left[I^{*}\right] \\
0 & K_{\mathfrak{M} \theta}\left[l^{2}\right]
\end{array}\right]\left\{\begin{array}{l}
\{\rho\} \\
\{\theta\}
\end{array}\right\} .
$$

By the Eqs. (8)-(11), the unknown forces and moments on the pile head are expressed by means of 3 displacement and 3 rotational components of an ideally rigid pile cap.

\subsection{Equilibrium equations in global coordinate system}

If the influence of the piles on the cap are replaced by unknown internal forces on the pile head $\{N\},\{T\},\{M\}$ 
and $\{M\}$, and then the conditions of equilibrium with the external forces $\{R\}$ and $\left\{M_{R}\right\}$ which acts on the cap are written, then two vector equations are obtained:

$$
\begin{aligned}
& \sum_{i}(\{N\}+\{T\})_{i}=\{R\} \\
& \sum_{i}(\{M\}+\{r\} \times(\{N\}+\{T\})+\{\mathfrak{M}\})_{i}=\left\{M_{R}\right\} .
\end{aligned}
$$

By replacing Eq. (8) into (12), and grouping the members beside the same vectors $\{\rho\}$ and $\{\theta\}$, two vector equations are obtained Eq. (13), where the only unknowns are the cap vector of displacement $\{\rho\}$ and rotation $\{\theta\}$.

$$
\begin{aligned}
& \sum_{i}\left(\Delta K_{R}\left[l^{2}\right]+K_{T t}[I]\right)_{i}\{\rho\}+ \\
& +\sum_{i}\left(\Delta K_{R}\left[l^{2}\right]\left[\otimes_{r}\right]+K_{T t}\left[\otimes_{r}\right]+K_{T \theta}\left[\otimes_{l}\right]\right)_{i}\{\theta\}=\{R\} \\
& \sum_{i}\left(-\Delta K_{R}\left[\otimes_{r}\right]\left[l^{2}\right]-K_{T t}\left[\otimes_{r}\right]-K_{M t}\left[\otimes_{l}\right]\right)_{i}\{\rho\}+ \\
& +\left(-\Delta K_{R}\left[\otimes_{r}\right]\left[l^{2}\right]\left[\otimes_{r}\right]+K_{T t}\left[\otimes_{r}\right]^{2}-K_{T \theta}\left[\otimes_{r}\right]\left[\otimes_{l}\right]-\right. \\
& \left.-K_{M t}\left[\otimes_{l}\right]\left[\otimes_{r}\right]+\Delta K_{M}\left[l^{2}\right]+K_{M \theta}[I]\right)_{i}\{\theta\}=\left\{M_{R}\right\} \\
& \Delta K_{R}=K_{N s}-K_{T t}, \quad \Delta K_{M}=K_{\mathfrak{M} \theta}-K_{M \theta}
\end{aligned}
$$

When the pile-cap connections are hinged, the coefficients of stiffness $K_{T \theta}, K_{M t}, K_{M \theta}$ and $K_{M \theta}$ are equal to zero, so they should be omitted, after which the Eq. (13) became simpler Eq. (14).

$$
\begin{aligned}
& \sum_{i}\left(\Delta K_{R}\left[l^{2}\right]+K_{T t}[I]\right)_{i}\{\rho\}+ \\
& +\sum_{i}\left(\Delta K_{R}\left[l^{2}\right]\left[\otimes_{r}\right]+K_{T t}\left[\otimes_{r}\right]\right)_{i}\{\theta\}=\{R\} \\
& \sum_{i}\left(-\Delta K_{R}\left[\otimes_{r}\right]\left[l^{2}\right]-K_{T t}\left[\otimes_{r}\right]\right)_{i}\{\rho\}- \\
& -\sum_{i}\left(\Delta K_{R}\left[\otimes_{r}\right]\left[l^{2}\right]\left[\otimes_{r}\right]-K_{T t}\left[\otimes_{r}\right]^{2}\right)_{i}\{\theta\}=\left\{M_{R}\right\}
\end{aligned}
$$

After grouping the members beside the unknown vectors of displacement and rotation, the equations of equilibrium Eq. (13) can come up to a system of 6 algebraic equations, in which 3 unknown components of displacement and 3 unknown components of rotation of the cap appear.

$$
\begin{aligned}
& \left\{\begin{array}{c}
R_{x} \\
R_{y} \\
R_{z} \\
M_{R x} \\
M_{R y} \\
M_{R z}
\end{array}\right\}=\left[\begin{array}{llllll}
K_{11} & K_{12} & K_{13} & K_{14} & K_{15} & K_{16} \\
& K_{22} & K_{23} & K_{24} & K_{25} & K_{26} \\
& & K_{33} & K_{34} & K_{35} & K_{36} \\
& & & K_{44} & K_{45} & K_{46} \\
& & & & K_{55} & K_{56} \\
& & & & & K_{66}
\end{array}\right]\left\{\begin{array}{c}
u \\
v \\
w \\
\theta_{x} \\
\theta_{y} \\
\theta_{z}
\end{array}\right\} \\
& \{P\}=[K]\{U\}=[F]^{-1}\{U\}
\end{aligned}
$$

The stiffness matrix $[K]$ is symmetrical $\left(K_{i j}=K_{j i}\right)$, so in the Eq. (15) only the upper triangular scheme is shown. The external force $\{P\}$ includes the components of the resultant external forces and moments reduced to the global coordinate system origin $(\mathrm{O})$.

\subsection{Coefficients of flexibility/stiffness of the pile-soil}

The coefficients of stiffness for individual piles can be determined on the basis of the adopted deformable media, using analytical or numerical methods or based on the results of the pile load test. The simplest and mostly used is the Winkler model, which can be linearly or non-linearly deformable. In addition, more complex approach can be used based on the elastic or elasto-plastic continuum model.

It should be kept in mind, that the pile load test is mandatory for pile design. As a rule, there is always a test for vertical load, and very often because it does not require complex equipment, a test for horizontal load. When there are test load results, no analytical approach is required since the flexibility coefficients of the matrix $\left[F_{p}\right]$ in Eq. (7), can be reliably determined directly for the design load span. The maximum test load is, as a rule, the failure load or minimum twice the value of the service load.

$$
F_{s N}=\frac{s\left(N_{\text {design }}\right)}{N_{\text {design }}}, F_{t T}=\frac{t\left(T_{\text {design }}\right)}{T_{\text {design }}}, F_{\theta T}=\frac{\theta\left(T_{\text {design }}\right)}{T_{\text {design }}}
$$

In order to complete the matrix $\left[F_{p}\right]$, it would also be necessary to carry out a load test with bending and torsional moment. Since such testing is rare and non-standard, the problem can be solved by an approach based on the Winkler model. Firstly, based on the results of penetration tests, it is estimated whether the deformability of the soil is nearly constant (over-consolidated clays) or roughly increases linearly with depth (soft clays and sands). After that, using the analytical expressions, an equivalent horizontal modulus of reaction $k_{h}$ or a gradient of horizontal modulus of reaction $n_{h}$ can be obtained. In most cases, the length of the pile is such that with a slight error, a solution for a long pile can be used.

For a long pile $\left(\lambda_{h} L>4\right)$ with free head, in the soil with constant modulus of reaction, loaded with horizontal force, the coefficients of flexibility according to Hetényi [5] are:

$$
\begin{aligned}
& k_{h}=\text { const }, \lambda_{h}=\left(\frac{k_{h} d}{4 E_{p} J}\right)^{1 / 4} \\
& F_{t T}=\frac{2 \lambda_{h}}{k_{h} d}, F_{\theta T}=F_{t M}=\frac{2 \lambda_{h}^{2}}{k_{h} d}, \quad F_{\theta M}=\frac{4 \lambda_{h}^{3}}{k_{h} d} .
\end{aligned}
$$


For a long free head pile $\left(\eta_{h} L>4\right)$ with linearly increasing modulus of reaction, and loaded with horizontal force, the coefficients of flexibility according to Barber [6] are:

$$
\begin{aligned}
& k_{h}=n_{h} \frac{z}{d}, \eta_{h}=\left(\frac{n_{h}}{E_{p} J}\right)^{1 / 5}, F_{t T}=\frac{2.40}{n_{h}^{0.6}\left(E_{p} I\right)^{0.4}} \\
& F_{t M}=F_{\theta T}=\frac{-1.60}{n_{h}^{0.4}\left(E_{p} I\right)^{0.6}}, F_{\theta M}=\frac{1.74}{n_{h}^{0.2}\left(E_{p} I\right)^{0.8}} .
\end{aligned}
$$

When the flexibility coefficients $F_{t T}$ and $F_{\theta T}$ are obtained by Eq. (16), the equivalent modulus $k_{h}$ or $n_{h}$ and flexibility coefficient $F_{\theta M}$ can be calculated by Eq. (17). The flexibility coefficient $F_{\theta M}$ is obtained by the solution for the torsionally loaded pile in elastic continuum (Poulos and Davis [31]) with constant or linearly increasing soil shear modulus.

For slenderness $L / d>20$, stiffness $10^{-1}<G_{p} I_{o} / G_{s} d^{4}<10^{3}$ or $10^{-1}<G_{p} I_{o} / n_{G} d^{5}<10^{4}$ the simple interpolation function can be derived for the pile-soil flexibility coefficient:

$$
\begin{aligned}
& G_{s}=\text { const }, K_{\mathfrak{M} \theta} \approx 2 d \sqrt{G_{p} G_{s} I_{o}}, k_{h} \approx 2 G_{s} / d \\
& G_{s}=n_{G} z, K_{\mathfrak{M} \theta} \approx \sqrt[3]{n_{G}\left(G_{p} I_{o} d\right)^{2}}, n_{h} \approx 2 n_{G} .
\end{aligned}
$$

In Eq. (19), $G_{p}$ is the shear modulus of the pile, $I_{o}$ is the polar moment of inertia, $\mathrm{d}$ is the width of the pile, $G_{s}$ and $n_{G}$ is the soil shear and gradient of the shear modulus along the pile shaft.

After the procedure described above, the elements of the flexibility matrix are determined, the stiffness matrix $\left[K_{p}\right]$ can be obtained as an inverse of the flexibility matrix $\left[F_{p}\right]$ according to the following:

$$
\left[K_{p}\right]=\left[\begin{array}{cccc}
K_{N s} & 0 & 0 & 0 \\
0 & K_{T t} & K_{T \theta} & 0 \\
0 & K_{M t} & K_{M \theta} & 0 \\
0 & 0 & 0 & K_{\mathfrak{M} \theta}
\end{array}\right],\left[F_{p}\right]=\left[\begin{array}{cccc}
F_{S N} & 0 & 0 & 0 \\
0 & F_{t T} & F_{\theta T} & 0 \\
0 & F_{t M} & F_{\theta M} & 0 \\
0 & 0 & 0 & F_{\theta \mathfrak{M}}
\end{array}\right] .
$$

When the stiffness matrices of the pile-soil system are determined for all piles, it is possible to calculate the cap displacement and rotation for arbitrary loading. Strictly speaking, because of the drawback of the Winkler model, the obtained result is without interaction between the piles, that is valid only at large mutual pile distance $(e / d>$ min 6-8), what is extremely rare in practice.

\section{Interaction between piles}

The main drawback of the Winkler model is no interaction between piles, what makes it impossible to obtain the direct solution for the displacement and rotation of the pile group. This deficiency could be solved in an approximate way by reducing the modulus of reaction for certain piles in the group, according mainly to their geometrical arrangement.

\subsection{Interaction between piles for vertical loading}

At axially loaded pile group, as a rule, the influence of their interaction on the settlement should be taken into account. This influence is introduced in Winkler's model by reducing the coefficient of pile stiffness. The reduction coefficient depends on the position of the pile, the pile length, the layout and the mutual distance of the piles and the load distribution between pile base and shaft. The force redistribution in the piles and settlement increase due to their interaction can be obtained using the interaction factors proposed by Mandolini and Viggiani [23] in the form:

$\alpha_{i j}=A\left(\frac{e_{i j}}{d}\right)^{-B}, \alpha_{i j}=C+D \cdot \ln \left(\frac{e_{i j}}{d}\right), \alpha_{i i}=1$.

In Eq. (21), $\alpha_{i j}$ is the interaction factor between pile $\mathrm{i}-\mathrm{j}, \mathrm{d}$ is the pile diameter, and $e_{i j}$ is the mutual distance. The coefficients A-D can be determined by pile load test. Alternatively, there are other, more complex methods, of which the term by Randolph and Wroth [22] is often used:

$\alpha_{i j}=\xi \frac{\ln \left(r_{m} / e_{i j}\right)}{\ln \left(2 r_{m} / d\right)}, r_{m}=2.5 L \rho\left(1-v_{s}\right), \quad \rho=\frac{G_{s}}{G_{b}}$.

In Eq. (22), $\xi$ is the diffraction factor (Mylonakis and Gazetas, 1998[32]), $r_{m}$ is the influence radius, $v_{s}$ is the Poisson's ratio, $\rho$ is the coefficient of soil inhomogeneity, and $G_{b}$ is the soil shear modulus at the pile base.

The diffraction factor $\xi$ contains the pile axial stiffness and slenderness, the soil shear modulus along the shaft and beneath the pile base. The size of the diffraction factor can be approached by diagram in Fig. 4, using the following input values (Eq. 23):

$$
\begin{aligned}
& \lambda_{\tau}=\sqrt{\frac{k_{\tau} S}{E_{p} A}}, \frac{k_{b}}{G_{b}} \approx \frac{2}{1-v_{b}} \frac{1}{d_{b}} \\
& \Omega=\frac{k_{b} A_{b}}{\lambda_{\tau} E_{p} A}, \frac{k_{\tau}}{G_{s}} \approx \frac{1.3}{d \pi}\left(\frac{E_{p}}{E_{s}}\right)^{\frac{-1}{40}}\left(1+7\left(\frac{L}{d}\right)^{-0.6}\right) .
\end{aligned}
$$

For slender piles, the diffraction factor is 0.5 , for free standing piles is between $0-0.5$, and for floating piles is between $0.5-1.0$. After the factors of interaction have been obtained by Eq. (21) or in some other way, the axial stiffness coefficients of the pile-soil system for the group is obtained by the following: 


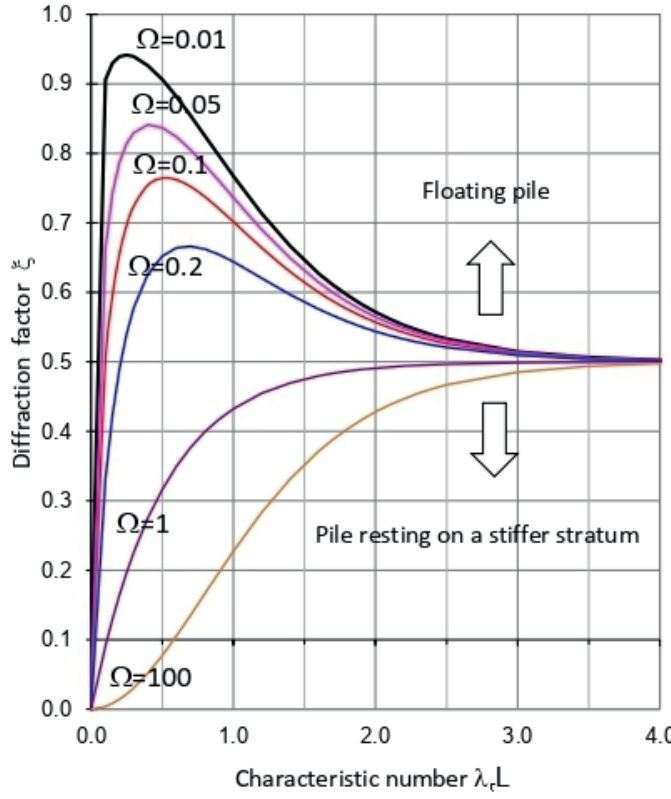

Fig. 4 Diffraction factor $\xi$ vs. characteristic number $\lambda_{t} L$

$$
\left\{K_{N s}\right\}=K_{N s}[\alpha]^{-1}\{I\}, R_{S}=\frac{n}{\sum_{i} \sum_{j} \alpha_{i j}^{-1}} .
$$

In Eq. (24), $[\alpha]$ is the matrix of interaction factors, $K_{N s}$ is the pile-soil axial stiffness without interaction and $K_{N s, i}$ is the reduced axial stiffness due to piles interaction. $R_{s}$ is the settlement factor for vertically loaded pile group, which represents the ratio of the settlement of the group and the individual pile, under the same average load.

\subsection{Interaction between piles for horizontal loading}

For horizontally loaded pile group in Winkler model, the effect of the group on lateral displacement can be taken approximately, by reducing the pile stiffness coefficient, according to their position and distance in the group. The method for reducing the stiffness of the pile-soil system for calculating the lateral displacement is known as "method of the p-multiplier". A similar procedure by Smoltczyk [33] is used here. For long piles, with constant or linearly varying soil modulus of reaction, the reduction for the pile (i) in the group, for horizontal force $H_{x}$ in the $+x$ direction is:

$k_{h, i}=k_{h}\left(\alpha_{x} \alpha_{y}\right)_{i}^{4 / 3}, n_{h, i}=n_{h}\left(\alpha_{x} \alpha_{y}\right)_{i}^{5 / 3}$.

The coefficients of reduction $\alpha$ depend of pile position and force direction. There are two types of coefficients, that is, $\alpha_{x}$ which depends on the distance $e_{x}$ in the direction of the force and $\alpha_{y A}$ and $\alpha_{y z}$ which depend on the distance $e_{y}$ in the direction normal to the direction of force (Eq. 26).

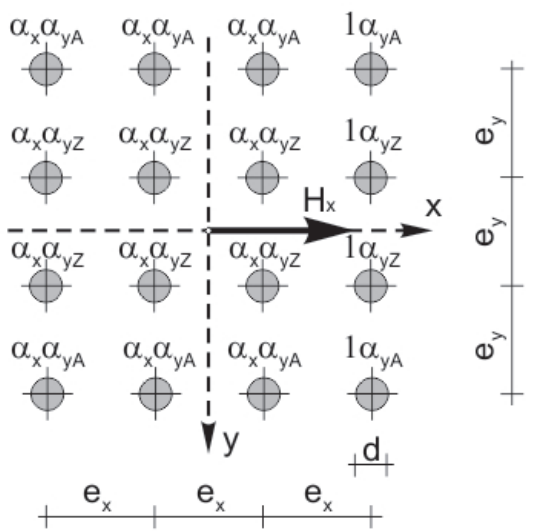

Fig. 5 Reduction factors a for horizontal modulus of reaction $k_{h}$ and $n_{h}$

For the entire head column, the coefficient $\alpha_{x}=1$ while for all subsequent columns is $\alpha_{x}<1$. The coefficients $\alpha_{y A}$ are the same for outmost lateral row of piles and the coefficients $\alpha_{y z}$ are the same for all inner rows. The rows are parallel with the force direction (Fig. 5). If the distance of in the direction normal to the force is $e_{y} / d \geq 3$ the reduction coefficients are $\alpha_{y A}=\alpha_{y z}=1$. If the distance of the piles in the force direction is $e_{x} / d \geq 6$ the reduction coefficient is $\alpha_{x}=1$.

$$
\begin{aligned}
& 2 \leq e_{x} / d \leq 6: \alpha_{x}=0.50+0.125\left(e_{x} / d-2\right) \\
& 2 \leq e_{y} / d \leq 3: \alpha_{y A}=0.90+0.10\left(e_{y} / d-2\right) \\
& 2 \leq e_{y} / d \leq 3: \alpha_{y Z}=0.75+0.25\left(e_{y} / d-2\right)
\end{aligned}
$$

The horizontal force is generally not parallel with axis but it already has an arbitrary angle $\varphi$ with the $\mathrm{x}$-axis. The reduction must be done particularly in the direction of both axes. Since two different values of the modules $\left(k_{h x}\right.$ and $k_{h y}$ or $n_{h x}$ and $n_{h y}$ ) cannot be entered for any pile in Eq. (15) simultaneously, the representative value must be used, according to the force angle $\varphi$. If the values $k_{h x}$ and $k_{h y}$ or $n_{h x}$ and $n_{h y}$ are understood as the main radius of the ellipse, then the value $k_{h \varphi}$ or $n_{h \varphi}$ is the radius of the ellipse in the horizontal force direction. Substituting $\tan (\varphi)=H_{y} / H_{x}$ and $h=k_{h x} / k_{h y}$ or $n_{h x} / n_{h y}$ the final expression is:

$$
k_{h \varphi}=k_{h x} \sqrt{\frac{1+\tan ^{2}(\varphi)}{1+\eta^{2} \tan ^{2}(\varphi)}}, n_{h \varphi}=n_{h x} \sqrt{\frac{1+\tan ^{2}(\varphi)}{1+\eta^{2} \tan ^{2}(\varphi)}} .
$$

According to Eq. (27) the value $k_{h \varphi}$ or $n_{h \varphi}$ for each pile in group, becomes a function of the position in group and direction of the horizontal force. It should be kept in mind that the angle $\mathrm{j}$ must always be between $0-\pi / 2$. If the force is directed $-x$ or $-y$, then modules must be adapted to obtain a logical results. After the reduced soil 
modulus for horizontal loading are obtained by Eq. (26) or in some other way, the reduced coefficients of lateral stiffness of the pile-soil system can be determined according to Eq. (28):

$$
\begin{aligned}
& K_{T t, i}=\frac{k_{h \varphi, i} d}{\lambda_{h \varphi, i}}, K_{T \theta, i}=K_{M t, i}=\frac{k_{h \varphi, i} d}{2 \lambda_{h \varphi, i}^{2}}, K_{M \theta, i}=\frac{k_{h \varphi, i} d}{2 \lambda_{h \varphi, i}^{3}} \\
& K_{T t, i}=1.08 n_{h \varphi, i}^{0.6}\left(E_{p} J\right)^{0.4}, K_{M \theta, i}=1.49 n_{h \varphi, i}^{0.2}\left(E_{p} J\right)^{0.8} \\
& K_{T \theta, i}=K_{M t, i}=n_{h \varphi, i}^{0.4}\left(E_{p} J\right)^{0.6} .
\end{aligned}
$$

Stiffness coefficients of the pile-soil, according to the Eq. (28), include not only the pile and soil stiffness but also their interaction with the horizontal force. Together with the coefficient of stiffness according to Eq. (24), which involves the interaction of the piles for axial force, according to Eq. (15), it is possible to calculate the forces

\section{References}

[1] Terzaghi, K. "Evaluation of Coefficients of Subgrade Reaction", Géotechnique, 5(4), pp. 297-326, 1955.

https://doi.org/10.1680/geot.1955.5.4.297

[2] Reese, L. C., Cox, W. R., Koop, F. D. "Analysis of Laterally Loaded Piles in Sand", In: Offshore Technology Conference, Houston, TX, USA, 1974, pp. 473-483.

https://doi.org/10.4043/2080-MS

[3] Robinson, K. "Horizontal Subgrade Reaction Estimated from Lateral Tests on Timber Piles", In: Lundgren, R. (ed.) Behavior of Deep Foundations, ASTM International, West Conshohocken, PA, USA, 1979, pp. 520-536. https://doi.org/10.1520/STP33749S

[4] Scott, R. F. "Foundation Analysis", Prentice-Hall, Upper Saddle River, NJ, USA, 1981.

[5] Hetényi, M. "Beams on elastic foundation: theory with applications in the fields of civil and mechanical engineering", University of Michigan Press, Ann Arbor, MI, USA, 1946.

[6] Barber, E. S. "Discussion to Paper by S.M. Gleser", ASTM Special Technical Publication, 154, pp. 96-99, 1953.

[7] Broms, B. B. "Design of Laterally Loaded Piles", Journal of the Soil Mechanics and Foundations Division, 91(3), pp. 79-99, 1965.

[8] Matlock, H. "Correlations for Design of Laterally Loaded pPiles in Soft Clay", In: Proceedings of the 2nd Annual Offshore Technology Conference, Houston, TX, USA, 1971, pp. 577-594. https://doi.org/10.4043/1204-ms

[9] Reese, C., Wang, T., Vasquez, L. "GROUP Version 7", [computer program] Available at: https://www.ensoftinc.com/ [Accessed: 10 January 2020]

[10] Bransby, M. F. "Selection of p-y curves for the design of single laterally loaded piles", International Journal for Numerical and Analytical Methods in Geomechanics, 23(15), pp. 1909-1926, 1999.

https://doi.org/10.1002/(SICI)1096-9853(19991225)23:15< 1909::AID-NAG26>3.0.CO;2-L and moments in the pile head and the displacement and rotation of the ideally rigid cap, due to the arbitrary spatial external loading.

\section{Conclusions}

The pile cap displacement estimation is undoubtedly very complex problems in geotechnics. Besides commercial software programs based on sophisticated numerical methods, in everyday practice simple solutions based on soil approximation by linear or nonlinear Winkler model are still widely used. The content of this paper is on that course, with a small modification when using soil parameters. It is known, that the pile load test is obligatory to evaluate the pile bearing capacity and displacement. Having that in mind, this paper presents the simple way to incorporate the pile load test results in the numerical model for pile group analysis in order to obtain highly reliable predictions.

[11] Ashour, M., Ardalan, H. "Employment of the P-Multiplier in PileGroup Analysis", Journal of Bridge Engineering, 16(5), pp. 612623, 2011. https://doi.org/10.1061/(ASCE)BE.1943-5592.0000196

[12] Prakash, S., Kumar, S. "Nonlinear Lateral Pile Deflection Prediction in Sands", Journal of Geotechnical Engineering, 122(2), pp. 130138, 1996. https://doi.org/10.1061/(ASCE)0733-9410(1996)122:2(130)

[13] Bowles, J. E. "Foundation analysis and design", McGraw-Hill, New York, NY, USA, 1997.

[14] Hsiung, Y. "Theoretical Elasto-Plastic Solution for Laterally Loaded Piles", Journal of Geotechnical and Geoenvironmental Engineering, 129(5), 2003. https://doi.org/10.1061/(ASCE)1090-0241(2003)129:6(475)

[15] Bouzid, Dj. A., Bhattacharya, S., Dash, S. R. "Winkler Springs (p-y curves) for pile design from stress-strain of soils: FE assessment of scaling coefficients using Mobilized Strength Design concept", Geomechanics and Engineering, 5(5), pp. 379-399, 2013. https://doi.org/10.12989/gae.2013.5.5.379

[16] Guo, W. D. "Vertically Loaded Single piles in Gibson Soil", Journal of Geotechnical and Geoenvironmental Engineering, 126(2), pp. 189-193, 2000. https://doi.org/10.1061/(ASCE)1090-0241(2000)126:2(189)

[17] Butterfield, R., Banerjee, P. K. "The Elastic Analysis of Compressible Pile and Pile Group", Géotechnique, 21(1), pp. 43-60, 1971. https://doi.org/10.1680/geot.1971.21.1.43

[18] Poulos, H. G., Randolph, M. F. "Pile Group Analysis: A Study of Two Methods", Journal of Geotechnical Engineering, 109(3), pp. 355-372, 1983. https://doi.org/10.1061/(ASCE)0733-9410(1983)109:3(355)

[19] Randolph, M. F. "Pile-soil interaction for dynamic and static loading", In: Niyama, S., Beim, J. (eds.) Application of Stress-Wave Theory to Piles - Quality Assurance on Land and Offshore Piling, CRC Press, Rotterdam, Netherlands, 2000, pp. 3-11. 
[20] Zhang, Q.-Q., Zhang, Z.-M., He, J.-Y. "A simplified approach for settlement analysis of single pile and pile groups considering interaction between identical piles in multi layered soils", Computers and Geotechnics, 37(7-8), pp. 969-976, 2010. https://doi.org/10.1016/j.compgeo.2010.08.003

[21] Higgins, W., Vasquez, C., Basu, D., Griffiths, D. V. "Elastic Solutions for Laterally Loaded Piles", Journal of Geotechnical and Geoenvironmental Engineering, 139(7), pp. 1096-1103, 2013. https://doi.org/10.1061/(ASCE)GT.1943-5606.0000828

[22] Randolph, M. F., Wroth, C. P. "Analysis of the vertical deformation of pile groups", Geotechnique, 29(4), pp. 423-439, 1979. https://doi.org/10.1680/geot.1979.29.4.423

[23] Mandolini, A., Viggiani, C. "Settlement of piled foundations", Géotechnique, 47(4), pp. 791-816, 1997. https://doi.org/10.1680/geot.1997.47.4.791

[24] Mokwa, R. L. "Investigation of the resistance of pile caps to lateral loading", Ph.D. Thesis, Virginia Polytechnic Institute and State University, 1999.

[25] Ilyas, T., Leung, C. F., Chow, Y. K., Budi, S. S. "Centrifuge Model Study of Laterally Loaded Pile Groups in Clay", Journal of Geotechnical and Geoenvironmental Engineering, 130(3), pp. 274 283,2004

https://doi.org/10.1061/(ASCE)1090-0241(2004)130:3(274)

[26] Ashour, M., Norris, G. "Modeling Lateral Soil-Pile Response Based on Soil-Pile Interaction", Journal of Geotechnical and Geoenvironmental Engineering, 126(5), pp. 420-428, 2000. https://doi.org/10.1061/(ASCE)1090-0241(2000)126:5(420)
[27] Banerjee, P. K. "Analysis of axially and laterally loaded pile groups", In: Scott, C. R. (ed.) Developments in soil mechanics, Applied Science Publishers, London, UK, 1978, pp. 317-346.

[28] Poulos, H. G. "Pile Group Settlement Estimation - Research to Practice", In: GeoShanghai International Conference, Shanghai, China, 2006, pp. 1-22. https://doi.org/10.1061/40865(197)1

[29] Mandolini, A., Russo, G., Viggiani, C. "Pile foundations: Experimental investigations analysis and design", Ground Engineering, 38(9), pp. 34-35, 2005.

[30] McCabe, B. A., Sheil, B. B. "Pile Group Settlement EstimationSuitability of Nonlinear Interaction Factors", International Journal of Geomechanics, 15(3), 2015. https://doi.org/10.1061/(ASCE)GM.1943-5622.0000395

[31] Poulos, H. G., Davis, E. H. "Pile foundation analysis and design", John Wiley \& Sons, New York, NY, USA, 1980.

[32] Mylonakis, G., Gazetas, G. "Settlement and additional internal forces of grouped piles in layered soil", Géotechnique, 48(1), pp. 55-72, 1998. https://doi.org/10.1680/geot.1998.48.1.55

[33] Smoltczyk, U. "Geotechnical Engineering Handbook", 3, Elements and Structures, Ernst \& Sohn, Berlin, Germany, 2003. 